\title{
Syntheses and Properties of Two Olefins, Six Paraffins, and Their Intermediates
}

\section{By Thomas W. Mears, Abraham Fookson, Philip Pomerantz, Edwin H. Rich, Cecil S. Dussinger, and Frank L. Howard}

\begin{abstract}
As a part of a study of the desirability of certain hydrocarbon types as jet fuel components, eight aliphatic hydrocarbons have been prepared and purified. This report describes their syntheses and those of several intermediates. Physical constants were measured on the high purity products.
\end{abstract}

\section{Introduction}

During the last few years, the advent of reaction engines has presented new fuel problems; one attack on these problems has been the study of the properties of fuel components. The work described herein is part of a project sponsored by the National Advisory Committee for Aeronautics at the National Bureau of Standards, in which certain hydrocarbons are prepared in high purity for tests at the NACA Flight Propulsion Research Laboratory (Cleveland). The tests were selected primarily to provide data regarding the desirability of certain hydrocarbon structures in jet engine fuels. This report describes the preparation and purification of eight hydrocarbons. Common physical constants are given for these hydrocarbons and for several intermediate compounds synthesized for use in their preparation. The methods used for determination of physical constants are given in an appendix at the end of the paper.

\section{Apparatus}

\section{Reaction Vessels}

The majority of the reactions were carried out in two 50-gal commercial kettles, one constructed of stainless steel and the other of glass-lined steel. These kettles were double-walled and arranged so that steam or water could be circulated between the walls to maintain the reaction at any temperature from $5^{\circ}$ to $150^{\circ} \mathrm{C}$. The kettles were fitted with glass-lined steel condensers and arranged so that the jacket water temperature could be regu- lated. In this manner the condenser could be made to act as a reflux condenser, a dephlegmating column, or a "goose neck" for distillation. Reagents were added to the kettles by means of 5 -gal glass-lined steel addition vessels and the rate of addition controlled by means of a neoprene compression valve. The reactions were stirred by means of either a slow-speed anchor type stirrer or by a high-speed Hastelloy propeller stirrer. The kettles were arranged so that reaction products could be distilled either from one to the other or into a 15-gal double-walled copper receiving vessel. Small-scale reactions were carried out in 5-liter glass flasks or 14-liter brass kettles.

\section{Dehydration Apparatus}

The dehydrations of the carbinols were carried out in the vapor phase, using aluminum oxide catalyst, at $400^{\circ} \mathrm{C}$ in the case of primary alcohols, and at $300^{\circ} \mathrm{C}$ in the case of secondary and tertiary alcohols. The aluminum oxide was contained in a stainless steel tube, 2 in. in diameter and 3.75 $\mathrm{ft}$ long. This tube was placed in a furnace made by winding $35 \mathrm{ft}$ of nichrome wire (1 ohm/ft) around a $3.25 \mathrm{ft}$ length of 2 -in. pipe. The temperature was regulated by means of a variable transformer and measured by means of a thermocouple in a well embedded in the alumina. The products of reaction were condensed in a copper tube condenser after leaving the reaction zone. Flow of material to the apparatus was governed by use of a modified automobile carburetor as a 
TABLE 1. Distillation columns ${ }^{\text {a }}$

\begin{tabular}{|c|c|c|c|c|}
\hline Still no. & Type & Size & Packing & Pot capacity \\
\hline $11 \ldots$ & Tota! reflux intermittent take-off & $\begin{array}{l}\mathrm{cm} \\
600 \times 5.1\end{array}$ & $\begin{array}{l}35 \text {-in. } 1 / 2 \text {-in. carbon raschig rings, then } 200 \text {-in. } 3 / 32 \text {-in stain- } \\
\text { less steel helices from } 0.010 \text {-in. wire }\end{array}$ & $\begin{array}{l}m l \\
\quad 75,000\end{array}$ \\
\hline $18 \ldots \ldots$ & Podbielniak Hypercal & $127 \times 2.5$ & Heli-grid & 250 to 5,000 \\
\hline 19 to $20 \ldots$ & do & $250 \times 2.5$ & do & 250 to 5,000 \\
\hline $21 \ldots$ & Total reflux variable take-off & $120 \times 3.5$ & $3 / 16$-in. glass helices & 22,000 \\
\hline 22 to $24 \ldots$ & _ $d \mathrm{~d}_{2}$ & $183 \times 2.5$ & $3 / 32$-in. stainless steel helices from 0.010 -in. wire & 5,000 \\
\hline 25 to $27 \ldots$ & - $\mathrm{d} 0$ & $183 \times 2.5$ & $3 / 16$-in. glass helices & 5,000 \\
\hline
\end{tabular}

a Columns 19 and 20 have been equipped with a device for taking a sample in the middle of the night, thereby giving three equal samples in a 24 -hr period. Both of these columns operate continuously with only occasional checking.

constant level device. To construct this apparatus, the carburetor was disassembled and all openings for special jets and pumps closed. Then a copper tube line was installed between the floatoperated needle valve and a reservoir placed about 12 in. above the carburetor. A large separatory funnel (1-liter or 3-liter) served well as a reservoir. The float chamber cover contained a hole for pressure equalization (breather hole), which was retained in the final set up. Product delivery to the furnace was effected by means of a copper tube from the float bowl outlet to the furnace tube. A small, brass needle valve was installed in this line to regulate rate of flow. By means of this apparatus a constant-rate flow has been maintained for periods of several days during which no adjustments were necessary.

This same apparatus has been found to work well in reduced pressure experiments. In this case a line connected the top of the reservoir, the float bowl cover (breather hole), and the furnace tube. This line served to equalize the pressure in the three units of the system.

\section{Hydrogenators}

Hydrogenation of olefins was accomplished in high-pressure hydrogenators of the type described by Adkins [1]. ${ }^{1} \quad$ Bombs of 3- and 20-liter capacity were used. Use of commercial nickel-on-kieselguhr catalyst gave no difficulty in any of the hydrogenations, the extreme conditions being 1,500 $\mathrm{lb} /$ in. $^{2}$ pressure and a temperature of $160^{\circ} \mathrm{C}$.

\section{Stills}

All the stills used in these preparations have been previously described [6]. For convenience the salient features of each are listed in table 1 .

\footnotetext{
${ }_{1}^{1}$ Figures in brackets indicate the literature references at the end of this paper.
}

\section{Methods and Technique}

\section{Preparation of Grignard Reagents}

The preparation of Grignard reagents in large quantities (up to 300 moles) has been previously reported [6]. In the present syntheses a more or less general procedure for the preparation, coupling, and hydrolysis of the Grignard reagent was used. This general synthesis is given below, using the $n$-butyl magnesium chloride synthesis of 5-nonanol as an example (see sec. IV, 1).

\section{Determination of Physical Properties}

The apparatus and technique for the determination of the freezing point, boiling point, refractive index, and density are described in the appendix. The final products (paraffin hydrocarbons) were filtered through silica gel before measurement of physical properties. The physical properties of the best sample are given in table 2.

The method for determining the quality of each distilled sample and the criteria for the grouping of these samples has been to plot the boiling point and refractive index against the volume distilled, and to regard fractions comprising the flat "plateaus" as pure substances. Freezing points spotted at intervals along these plateaus aided in finding the purest sample for physical properties. Recently this method has been supplemented by the use of the difference in refractive index of each sample in relation to an arbitrarily selected reference sample. This property has been measured by means of a Rayleigh interferometer and has been found to be as sensitive to the purity of the sample as the freezing point and in some cases more sensitive. This method takes considerably less time than the freezing point determination and therefore can be applied to every fraction. 
This not only helps to find the best fraction but also identifies certain isolated "poor" fractions that occasional freezing points might overlook. Another advantage of the interferometer is that it permits a critical study of the distillation of substances that freeze with difficulty or not at all.

\section{Preparation of Materials}

\section{1. $n$-Nonane}

$n$-Nonane was prepared in three steps: (a) methyl formate was reacted with $n$-butylmagnesium chloride to yield 5-nonanol; (b) 5-nonanol was dehydrated to give a mixture of nonenes; (c) the mixed nonenes were hydrogenated to $n$-nonane.

5-Nonanol. 5-nonanol was prepared by means of a modification of the preparation given in Organic Syntheses [8].

Magnesium turnings (6.08 kg, $250 \mathrm{~g}$ atoms) were placed in the reactor and covered with 16 liters of ether To this was added about a liter of $n$-butyl chloride and a few crystals of iodine. The mixture was allowed to stand without stirring for about $1 / 2 \mathrm{hr}$, while the reaction started. During the next $2 \mathrm{hr}$ approximately $6 \mathrm{~kg}$ of $n$-butyl chloride was added while the reaction mixture was stirred and cooled. The reaction was then diluted with 48 liters of ether and the remainder of the $n$-butyl chloride added. A total of $25.8 \mathrm{~kg}$ (278 moles) of $n$-butyl chloride was added over a period of $6 \frac{1}{2} \mathrm{hr}$. The apparent excess of $n$-butyl chloride was to compensate for material lost through the condenser during the initial stages of the reaction.

To the Grignard reagent was added $7.5 \mathrm{~kg}(125$ moles) of methyl formate in 16 liters of ether. The rate of addition was rapid enough to maintain a brisk reflux and addition was completed in $5 \mathrm{hr}$. The reaction mixture became so thick that it was necessary to add 30 liters of ether and work the reaction mixture with a wooden paddle in order to loosen the stirrer.

The mixture was hydrolyzed with 18 liters of water followed by 75 liters of 18-percent sulfuric acid. During this time any ether that volatilized was allowed to distill off and was collected. A large quantity of magnesium sulfate settled out, and the major portion of the aqueous layer saturated with magnesium sulfate was siphoned off. An additional 35 liters of water was added to the mixture in the original kettle to bring the magnesium sulfate into solution and 50 liters of ether removed by distillation. The magnesium sulfate solution was siphoned off leaving the crude

TABLE 2. Physical properties of compounds prepared

\begin{tabular}{|c|c|c|c|c|c|c|c|c|c|c|}
\hline \multirow{2}{*}{ Compound } & \multirow{2}{*}{$\begin{array}{l}\text { Freezing } \\
\text { point }\end{array}$} & \multirow{2}{*}{$\begin{array}{c}\text { Boiling } \\
\text { point at } \\
760 \mathrm{~mm} \mathrm{Hg}\end{array}$} & \multirow{2}{*}{$\begin{array}{l}d t / d p \\
\text { at } 760 \\
m m ~ H g\end{array}$} & \multirow{2}{*}{$\begin{array}{l}\text { Boiling } \\
\text { range, } \\
20 \text { to } 80 \% \\
\text { distilled }\end{array}$} & \multicolumn{3}{|c|}{ Density } & \multicolumn{3}{|c|}{ Refractive index } \\
\hline & & & & & at $20^{\circ} \mathrm{C}$ & at $25^{\circ} \mathrm{C}$ & $d D / d t$ & at $20^{\circ} \mathrm{C}$ & at $25^{\circ} \mathrm{C}$ & $d n / d t$ \\
\hline & ${ }^{\circ} \mathrm{C}$ & ${ }^{\circ} \mathrm{C}$ & ${ }^{\circ} \mathrm{C} / \mathrm{mm}$ & ${ }^{\circ} \mathrm{C}$ & $g / m l$ & $g / m l$ & $(g / m l) /{ }^{\circ} C$ & $n_{\mathrm{D}}^{20}$ & $n_{\mathrm{D}}^{25}$ & per ${ }^{\circ} \mathrm{C}$ \\
\hline 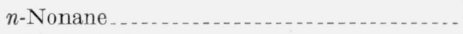 & -53.528 & 150.770 & 0.0483 & 0.008 & 0.71758 & 0.71367 & -0.000781 & 1. 40541 & 1. 40305 & -0.000472 \\
\hline 2-Methyloctane........ & -80.396 & 143.263 & .0480 & .014 & .71346 & .70961 & -.000771 & 1. 40307 & 1. 40079 & -.000456 \\
\hline 3,3-Dimethylheptane.... & (a) & 137.012 & .0489 & .007 & .72560 & .72163 & -.000793 & 1. 40878 & 1. 40631 & -.000494 \\
\hline$n$-Decane & -29669 & 174.119 & .0514 & .013 & .72987 & .72608 & -.000758 & 1. 41184 & 1. 40943 & -.000484 \\
\hline 2-Methylnonane ....... & -74.65 & 167.00 & .052 & .023 & .72636 & .72250 & -.000772 & 1. 41000 & 1. 40752 & -.000496 \\
\hline 2,3-Dimethylortane . . . . . . . . . & (a) & 164.31 & .051 & .027 & .73793 & .73414 & -.000757 & 1. 41491 & 1. 41266 & -.000450 \\
\hline 1-Hexene & -139.9 & 63.49 & .042 & .007 & .6732 & .6684 & -.00096 & 1. 3879 & 1. 3850 & -.00057 \\
\hline 4-Methyl-1-pentene & -153.95 & 53.89 & .042 & .025 & .6638 & .6589 & -.00098 & 1.3826 & 1.3797 & -.00058 \\
\hline 2-Methyl-1-octene & -77.86 & 144.85 & .048 & .12 & .7343 & .7303 & -.00081 & 1. 4184 & 1.4160 & -.00048 \\
\hline 1-Decene-1 & -66.64 & 170.60 & .053 & .097 & .7410 & .7371 & -.00077 & 1. 4216 & 1.4190 & -.00051 \\
\hline 2-Methyl-2-nonene & ........... & 171 & .06 & -..... & .7487 & .7447 & -.00078 & 1. 4288 & 1. 4264 & -.00048 \\
\hline 2-Methyl-3-nonene...... & (n) & 161.0 & .05 & 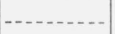 & .7340 & .7302 & -.00076 & 1. 4202 & 1. 4178 & -.00048 \\
\hline 2,3-Dimethyl-3-octene $\ldots$ & & 161.5 & .05 & - n & .7690 & .7651 & -.00080 & 1. 4267 & 1. 4242 & -.00049 \\
\hline 5-Nonanol & +5.6 & $\begin{array}{l}195.09 \\
\text { b } 145\end{array}$ & $\begin{array}{l}.046 \\
\text { c. } 18\end{array}$ & .007 & .8220 & .8183 & -.00074 & 1.4295 & 1. 4267 & -.00055 \\
\hline 2-Methyl-3-nonanol & & $\left\{\begin{array}{l}208.4 \\
\text { b } 154\end{array}\right.$ & $\begin{array}{l}.05 \\
\text { c. } 20\end{array}$ & & .8281 & .8245 & -.00073 & 1. 4343 & 1. 4320 & -.00045 \\
\hline 2,3-Dimethyl-3-octanol . & & $\left\{\begin{array}{l}189.1 \\
\text { b } 138\end{array}\right.$ & $\begin{array}{r}.05 \\
\text { c. } 19\end{array}$ & & .8293 & .8249 & -.00089 & 1. 4375 & 1. 4351 & -.00049 \\
\hline 3-Methyl-2-butanone & -94.4 & 94.2 & .046 & .93 & .8100 & .8061 & -.00078 & 1. 3887 & 1. 3861 & -.00053 \\
\hline
\end{tabular}

s Did not freeze, glassy at low temperatures.

b Boiling point at $150 \mathrm{~mm} \mathrm{Hg}$.

- $d t^{\prime} d p$ at $150 \mathrm{~mm} \mathrm{Hg}$. 
carbinol. The magnesium sulfate solutions were combined and extracted with 24 liters of distilled ether to recover any dissolved carbinol. The ether extract was added to the bulk of the crude carbinol in the original kettle and the ether removed by distillation. The crude carbinol was refluxed with 130 liters of 15-percent potassium hydroxide and finally removed by steam distillation. A total of 18.5 liters of crude carbinol was obtained.

The crude organic material was fractionated at $130 \mathrm{~mm} \mathrm{Hg}$ in column 25. From this distillation there was isolated methyl valerate, bp $74^{\circ}$ to $79^{\circ}$ C, $n_{D}^{20} 1.4003,0.78 \mathrm{~kg}$; $n$-amyl alcohol, bp $92^{\circ}$ to $94^{\circ} \mathrm{C}, n_{D}^{20} 1.4101,0.24 \mathrm{~kg}$; and 5-nonanol, bp $133^{\circ}$ to $138^{\circ} \mathrm{C}, 10.82 \mathrm{~kg}$. This represents a 60 -percent yield of 5-nonanol. A charge of the crude organic material was fractionated in column 8 , and the results of this distillation are shown in figure 1 . Cut A represents the methyl valerate, Cut B, $n$-amyl alcohol, and Cut C, 5-nonanol.

Nonenes. The dehydration of 5 -nonanol was accomplished using aluminum oxide catalyst at $285^{\circ}$ to $325^{\circ} \mathrm{C}$. From $6.54 \mathrm{~kg}$ (45.3 moles) of 5 -nonanol there was obtained $656 \mathrm{ml}$ of water $(80 \%)$ and about 7.75 liters of organic material. The organic material was distilled in column 22 to give $5.06 \mathrm{~kg}$ (40.2 moles) of nonenes, bp $140^{\circ}$ to $150^{\circ} \mathrm{C}$. This represents 88 percent dehydration on the basis of carbinol used.

A charge of $2,350 \mathrm{ml}$ of nonene was fractionated in column $20 \mathrm{in}$ an attempt to obtain high-purity samples for physical properties. The greater part of the olefin boiled at $148^{\circ}$ to $149^{\circ} \mathrm{C}$ (uncorrected) but the refractive index $\left(n_{D}^{20}\right)$ dropped steadily from

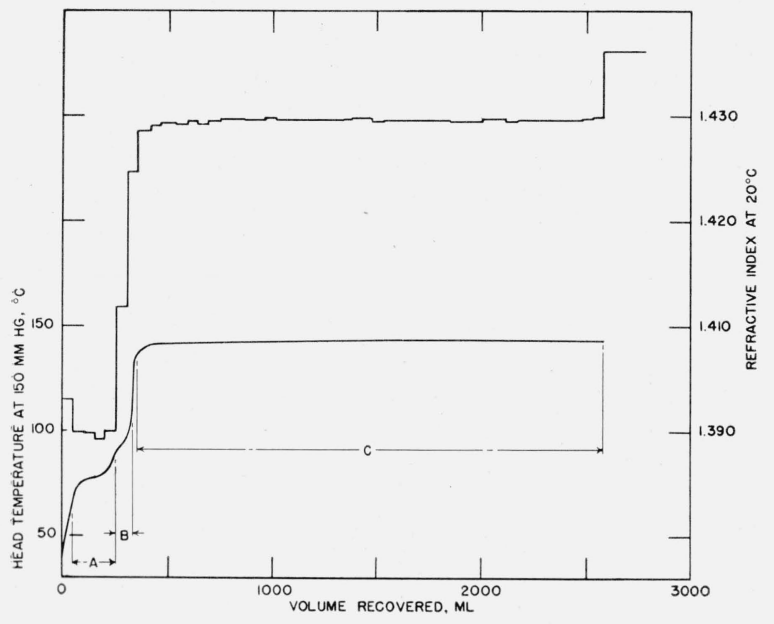

Figure 1. Distillation of 5-nonanol.

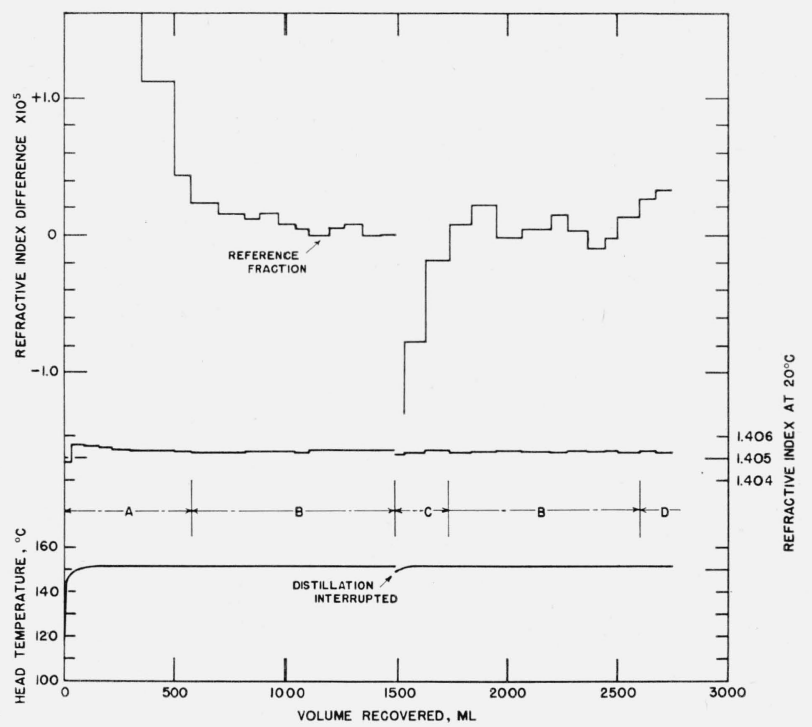

Figure 2. Distillation of n-nonane.

1.4207 to 1.4199 . This is to be expected since the boiling points of the geometric isomers of both 4-nonene and 3-nonene are very close together.

$n$-Nonane. The mixed nonenes $(4.40 \mathrm{~kg}, 34.9$ moles) were hydrogenated in the 20-liter hydrogenator using nickel-on-kieselguhr catalyst at $140^{\circ}$ to $160^{\circ} \mathrm{C}$. The initial pressure was $1,350 \mathrm{lb} / \mathrm{in}^{2}$ From this operation there was obtained $4.06 \mathrm{~kg}$ (31.8 moles) of $n$-nonane. This corresponds to a 91-percent yield.

The crude $n$-nonane was distilled in two separate charges in column 19. The results for one charge are shown in figure 2. Here the usefulness of the interferometer is apparent, showing the lower purity of the samples immediately following the point at which the still was accidently turned off. Portion $\mathrm{B}$ was collected as $n$-nonane, bp $151^{\circ} \mathrm{C}$, $n_{D}^{20} 1.4052-53$. The purified material from both runs was combined to give $2.38 \mathrm{~kg}$ of $n$-nonane, fp $-53.528^{\circ} \mathrm{C}$. This corresponds to a purity of approximately 99.9 mole percent $[5,11]$. In addition, a sample of the purest material was reserved for the measurement of physical constants.

\section{2-Methyloctane}

This nonane was prepared by the coupling of $n$-amylmagnesium chloride and methallyl chloride followed by hydrogenation of the resulting 2-methyl-1-octene.

2-Methyl-1-octene. n-Amylmagnesium chloride was prepared from $20 \mathrm{~kg}$ (188 moles) of $n$-amyl 
chloride and $4.52 \mathrm{~kg}$ (188 g atom) of magnesium using 56 liters of ether as solvent in the same manner as described in the preparation of 5nonanol. The methallyl chloride was added in ether solution over a period of 4 days and the reaction mixture allowed to stand for 3 weeks. At the end of this time the Gilman test [4] was negative for Grignard reagent.

The reaction mixture was hydrolyzed in the usual manner and the ether distilled from the reaction kettle. There remained 32 liters of crude organic product. This material was roughly fractionated in columns 25,26 , and 27 into three fractions: bp $35^{\circ}$ to $55^{\circ} \mathrm{C}, 4,890 \mathrm{ml}$; bp $55^{\circ}$ to $140^{\circ} \mathrm{C}, 11,330 \mathrm{ml}$; and bp $140^{\circ}$ to $150^{\circ} \mathrm{C}, 9,830$ $\mathrm{ml}$. The latter two fractions were redistilled and two major fractions collected, boiling at $110^{\circ}$ to $114^{\circ} \mathrm{C}$ and $140^{\circ}$ to $150^{\circ} \mathrm{C}$. The fraction boiling at $140^{\circ}$ to $150^{\circ} \mathrm{C}$ contained the 2-methyl-1-octene, $10.7 \mathrm{~kg}, 84.5$ moles, 45-percent yield. The other major fraction, boiling $110^{\circ}$ to $114^{\circ} \mathrm{C}$, was apparently a coupling product of two molecules of methallyl chloride. In order to obtain a sample for measurement of physical constants, $3,720 \mathrm{ml}$ of crude 2-methyl-1-octene was distilled in column 19. From this distillation there was obtained $2,400 \mathrm{ml}$ of 2 -methyl-1-octene, bp $143.5^{\circ}$ to $145.0^{\circ}$ $\mathrm{C}$ (uncorrected), $n_{D}^{20} 1.4185-86$, in addition to the sample for physical properties.

2-Methyloctane. The 2-methyl-1-octene $(4.7 \mathrm{~kg}$, 37 moles) was hydrogenated at $140^{\circ}$ to $150^{\circ} \mathrm{C}$ using nickel-on-kieselguhr catalyst. The initial pressure was $1,000 \mathrm{lb} /$ in. $^{2}$ at $25^{\circ} \mathrm{C}$. The resulting 2-methyloctane $(6,320 \mathrm{ml}, 4.49 \mathrm{~kg}, 35$ moles $)$ was distilled in column 20 in two charges. From these two distillations there was obtained $3.68 \mathrm{~kg}$ of purified 2-methyloctane, bp $142.5^{\circ}$ to $144^{\circ} \mathrm{C}$ (uncorrected), $n_{D}^{20} 1.4031$ to 1.4034. These samples were further classified by means of the differential refractive index in order to obtain the purest material for shipment. In this manner $1.53 \mathrm{~kg}$ of purified 2-methyloctane, fp $-80.42^{\circ}$ C, was obtained. This corresponds to a purity of approximately 99.8 percent [5]. In addition, a sample of the purest material was reserved for physical constants.

\section{3,3-Dimethylheptane}

This hydrocarbon was prepared by the coupling of $n$-butylmagnesium chloride with tert-amyl chloride.
The $n$-butylmagnesium chloride was prepared from $23.1 \mathrm{~kg}$ (250 moles) of $n$-butyl chloride and $6.08 \mathrm{~kg}$ (250 g atom) of magnesium using 75 liters of ether as solvent.

The solution of Grignard reagent was cooled to $10^{\circ} \mathrm{C}$ and tert-amyl chloride was added at the rate of $4.5 \mathrm{~kg}$ per day with constant stirring. A total of $23.9 \mathrm{~kg}$ ( 225 moles) of tert-amyl chloride was added over a period of 6 days. A heavy, white precipitate developed but the mixture remained fluid. The reaction mixture stood for 1 month before a negative Gilman test [4] was obtained. During this time the reaction was warmed to room temperature during the day and cooled at night. The mixture in the reaction kettle was worked up in the usual manner and some of the ether stripped off. From these operations there was obtained approximately 30 liters of crude organic material. This material was distilled in columns 22,23 , and 24 , and the following fractions were obtained: bp less than $70^{\circ} \mathrm{C}$, 16 liters (mostly ether); bp $70^{\circ}$ to $130^{\circ} \mathrm{C}, 3.6$ liters; bp $130^{\circ}$ to $145^{\circ} \mathrm{C}, 7.2$ liters (crude 3,3dimethylheptane); and heavy residue 1.5 liters.

The crude 3,3-dimethylheptane gave a positive test for halogen [3]. Therefore the crude paraffin was divided into two parts, one of which was treated with alcoholic potassium hydroxide, while the other was treated with sodium in liquid ammonia. Both treated samples proved to be free from halogen and were distilled in two charges of $3,400 \mathrm{ml}$ each in column 20. The distillation curve for one charge is shown in figure 3.

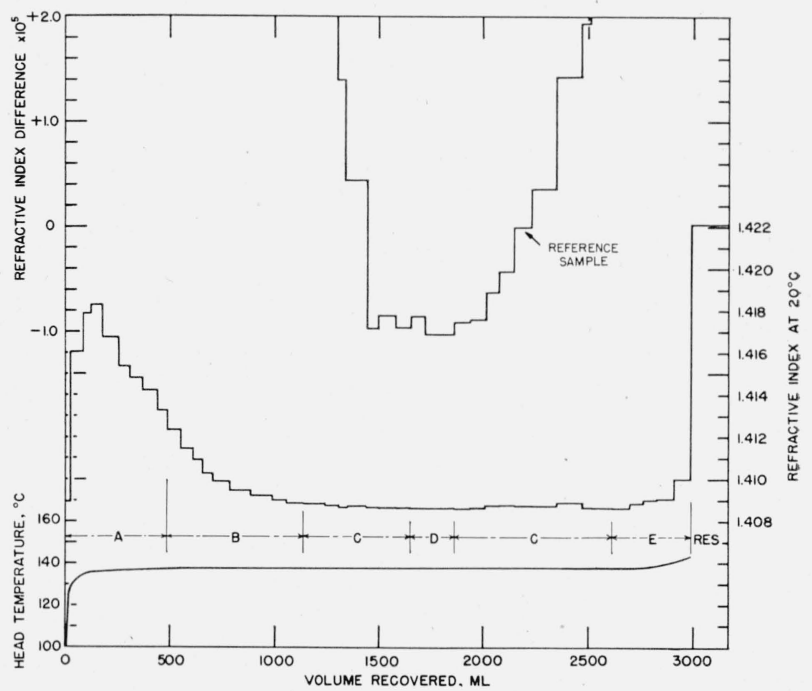

Figure 3. Distillation of 3,3-dimethylheptane. 
From the distillation curve it is apparent that there is some compound of higher refractive index boiling only slightly lower than 3,3-dimethylheptane. Portion $\mathrm{C}$ was taken as the purified 3,3-dimethylheptane. Portion D was reserved for the measurement of physical properties.

From these two distillations there was obtained $2,710 \mathrm{ml}(1.91 \mathrm{~kg})$ of material for shipment, bp $137.01^{\circ} \mathrm{C}$, boiling range (20 to 80 percent) $0.007^{\circ} \mathrm{C}, n_{D}{ }^{20} 1.40872$, in addition to a sample for physical properties.

\section{4. $n$-Decane}

$n$-Decane was prepared by the hydrogenation of 1-decene.

1-Decene. The 1-decene $(9.1 \mathrm{~kg})$ was obtained from commercial sources. A trial charge of this material $(3,600 \mathrm{ml})$ was fractionated in column 18 in order to obtain a sample for physical properties and also to determine the amount of impurities in the crude decene. From the data obtained it was decided to distill the remaining crude 1-decene in columns 25 to 27 and to discard the first and last 10 percent. The forerun and residue from these runs were combined and refractionated and it was found that $1,195 \mathrm{ml}$ of this material was satisfactory for hydrogenation. A total of 10.1 liters of 1-decene was obtained for hydrogenation in addition to a sample for physical properties.

$n$-Decane. Hydrogenation of the 1-decene (4.65 $\mathrm{kg}$ ) was carried out at $170^{\circ} \mathrm{C}$ using nickel-onkieselguhr catalyst. The reaction proceeded so rapidly that $500 \mathrm{lb} / \mathrm{in}^{2}{ }^{2}$ hydrogen pressure was quite sufficient. From this hydrogenation 4.62 $\mathrm{kg}$ (97 percent) of $n$-decane was obtained. The $n$-decane was fractionated in column 20 . In two runs, $4.62 \mathrm{~kg}$ of $n$-decane was fractionated to yield $3.43 \mathrm{~kg}$ of $n$-decane, $\mathrm{fp}-29.678^{\circ} \mathrm{C}$. This corresponds to a purity of 99.9 mole percent $[5,12]$. In addition, a sample of the purest material was reserved for the measurement of physical constants.

\section{2-Methylnonane}

This hydrocarbon was prepared by the dehydration of 2-methyl-3-nonanol followed by the hydrogenation of the mixture of olefins.

2-Methyl-3-nonanol. This carbinol was prepared by the reaction of isopropylmagnesium chloride with $n$-heptaldehyde. Isopropylmagnesium chloride was prepared from $6.08 \mathrm{~kg}$ (250 g atom) of magnesium and $19.6 \mathrm{~kg}$ (250 moles) of isopropyl chloride over a period of $4 \mathrm{hr}$ followed by $2 \mathrm{hr}$ of stirring. To the Grignard reagent was added $26.5 \mathrm{~kg}$ (250 moles) of $n$-heptaldehyde. The initial reaction was quite vigorous and because of this the addition of the heptaldehyde took $12 \mathrm{hr}$. The reaction mixture was allowed to stand overnight, after which it was worked up in the usual manner and most of the ether stripped off in the reaction kettle. From this reaction there was obtained 42 liters of crude 2-methyl-3-nonanol.

The remaining ether was removed by distilling in column 21. A charge of $3,400 \mathrm{ml}$ of the crude carbinol was fractionated in column 18 at 150 $\mathrm{mm} \mathrm{Hg}$. The principal products of this distillation were: fractions 6 to 10 , bp $127^{\circ}$ to $143^{\circ} \mathrm{C}$, $n_{D}^{20} 1.4263-53,223 \mathrm{~g}$; and fractions 25 to 57 , bp $154^{\circ}$ to $155^{\circ} \mathrm{C}, n_{D}^{20} 1.4341-48,1,321 \mathrm{~g}$. The first cut (fractions 6 to 10 ) was principally 1-heptanol from the reduction of the heptaldehyde. The second cut (fractions 25 to 57 ) was the 2 methyl-3-nonanol fraction. A high boiling residue remained, which was probably an aldol of heptaldehyde, and was not investigated.

The remaining carbinol was fractionated at $170 \mathrm{~mm} \mathrm{Hg}$ in columns 25 to 27 . The total principal products of all distillations were: 1heptanol, $2.24 \mathrm{~kg}$ (19.3 moles, $7.7 \%$ ); 2-methyl3-nonanol, $21.7 \mathrm{~kg}$ (137.2 moles, $54.9 \%$ ); and residue, probably an aldol, $3.25 \mathrm{~kg}$ (14.2 moles, $11.4 \%$ ).

2-Methylnonenes. An attempt was made to dehydrate the 2-methyl-3-nonanol using the oxalic acid method of Mulliken, Wakeman, and Gerry [7]. However, no 2-methylnonene was obtained, and the first drop from the ASTM distillation of the product boiled at $170^{\circ} \mathrm{C}$ and the 40 -percent point was $220^{\circ} \mathrm{C}$. It is apparent that there was very extensive polymerization, therefore this method of dehydration was rejected.

The large scale dehydration made use of alumina at $300^{\circ}$ to $325^{\circ} \mathrm{C}$. In the course of 40 hr $7.26 \mathrm{~kg}$ (45.9 moles) of 2-methyl-3-nonanol was passed through the dehydrator and $630 \mathrm{ml}$ (35.0 moles, $76.5 \%)$ of water and $5.45 \mathrm{~kg}(38.9$ moles) of organic material were recovered.

A charge $(4,000 \mathrm{ml} 2.97 \mathrm{~kg})$ of the olefins was distilled in column 19. Data obtained on this distillation are shown in figure 4.

The dehydration of 2-methyl-3-nonanol might be expected to yield four decenes. The principal 


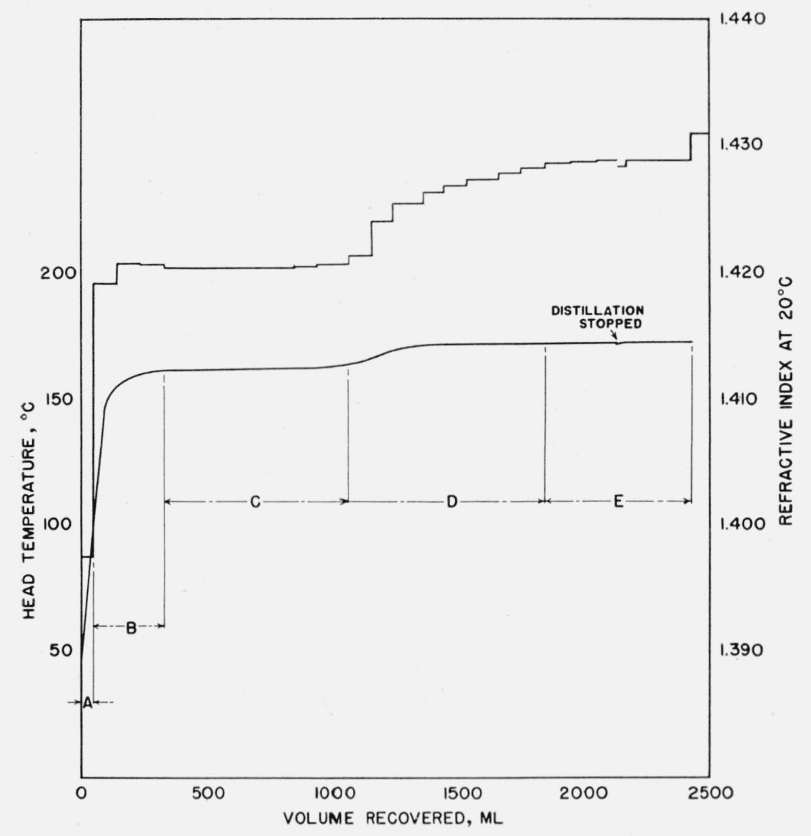

Figure 4. Distillation of olefins from the dehydration of 2-methyl-3-nonanol.

ones are 2-methyl-3-nonene, bp $163^{\circ} \mathrm{C}, n_{D}{ }^{20} 1.420$, and 2-methyl-2-nonene, bp $169.9^{\circ} \mathrm{C}, n_{D}{ }^{20} 1.4289$. The two expected in smaller quantities are 2-methyl-l-nonene, bp $168.2^{\circ} \mathrm{C}, n_{D}{ }^{20} 1.4241$, and 2-methyl-4-nonene, bp $163^{\circ} \mathrm{C}, n_{D}{ }^{20} 1.422$. Since there are no data available on the properties of these compounds they were calculated by the method of Francis [2]. These calculations seem to be valid qualitatively in figure 4 . The major flats at $C$ and $E$ represent 2-methyl-3-nonene and 2-methyl-2-nonene, respectively. Cut $B$, which boils slightly lower than the 2-methyl-3-nonene cut yet has a slightly higher refractive index, may be either 2-methyl-4-nonene or else the minor geometric isomer of 2-methyl-3-nonene. The abrupt rise of refractive index from $C$ coupled with the slow drifting into the flat at $E$ indicates the presence of a compound of slightly lower boiling point than 2-methyl-2-nonene with a refractive index considerably lower. This is probably the 2-methyl-1-nonene. The low-boiling cut $A$ is undoubtedly heptenes from the dehydration of the 1-heptanol. The residue is the undehydrated carbinol.

The remaining $3,570 \mathrm{ml}(2.48 \mathrm{~kg})$ was distilled in column 23 and the fraction boiling at $155^{\circ}$ to $175^{\circ} \mathrm{C}$ was collected as the methylnonenes. From both distillations, $3.43 \mathrm{~kg}$ (24.5 moles) of olefin was obtained for hydrogenation. The recovery of $1.05 \mathrm{~kg}$ of 2-methyl-3-nonanol indicated an efficiency of about 65 percent in the dehydration step instead of 76 percent as indicated by the recovered water.

2-Methylnonane. The mixed 2-methylnonenes were hydrogenated at $140^{\circ} \mathrm{C}$ using nickel-onkieselguhr catalyst. The starting hydrogen pressure was $600 \mathrm{lb} / \mathrm{in}^{2}$ The hydrogenation proceeded rapidly and was completed in $6 \mathrm{hr}$ to yield $3.29 \mathrm{~kg}$ (23.1 moles, $94 \%$ ) of 2-methylnonane.

The 2-methylnonane $(4,200 \mathrm{ml}, 3.08 \mathrm{~kg})$ was distilled in column 19 and from this distillation there was obtained $3,580 \mathrm{ml}$ of 2 -methylnonane, $\mathrm{mp}-74.82^{\circ} \mathrm{C}$. This corresponds to a purity of 99 mole percent $[5,10]$. In addition, a sample of the purest material was reserved for the determination of physical constants.

\section{2,3-Dimethyloctane}

This hydrocarbon was prepared by the dehydration of 2,3-dimethyl-3-octanol and hydrogenating the resulting olefins. The 2,3-dimethyl-3-octanol was prepared by the reaction of $n$-amylmagnesium chloride and 3-methyl-2-butanone.

3-Methyl-2-butanone. Methylisopropyl ketone was prepared by a modification of the method given in Organic Syntheses [9]. Tertiary amyl alcohol (10.6 kg 119 moles) was heated to $52^{\circ}$ to $53^{\circ} \mathrm{C}$ and $19.1 \mathrm{~kg}$ (119 moles) of bromine was added over a period of $5 \mathrm{hr}$. The resulting mixture was orange-red in color, and this color persisted upon the addition of another $1.4 \mathrm{~kg}$ of tert.-amyl alcohol. Water (32 liters) was added and the reaction mixture refluxed for 24 hours after which the organic material was steam distilled. The distillate was saturated with soda ash, the aqueous layer withdrawn and extracted with 3 liters of ether. The ether was stripped off and the residue added to the crude methylisopropyl ketone. This was distilled in columns 22 and 23 to give $6.76 \mathrm{~kg}$ (78.6 moles, $66 \%)$ of methylisopropyl ketone, bp $92^{\circ}$ to $95^{\circ} \mathrm{C}$.

2,3-Dimethyl-3-octanol. $n$-A m y l m a g n e si um chloride was prepared from $9.6 \mathrm{~kg}$ of $n$-amyl chloride (90 moles) and $6.95 \mathrm{~kg}$ of magnesium $(90 \mathrm{~g}$ atom) in the same manner as described in the preparation of $n$-butylmagnesium chloride in the synthesis of 5-nonanol. To the Grignard reagent was added $6.76 \mathrm{~kg}$ (78.6 moles) of methylisopropyl ketone over a period of $2 \mathrm{hr}$. The 
reaction mixture was stirred for the rest of the day and then worked up in the usual manner. The ether was stripped off and the crude carbinol distilled in column 22 at $130 \mathrm{~mm} \mathrm{Hg}$ pressure. The fraction boiling at $130^{\circ}$ to $135^{\circ} \mathrm{C}$ was collected as 2,3-dimethyl-3-octanol. From two distillations, $6 \mathrm{~kg}$ (37.9 moles, $48 \%)$ of 2,3-dimethyl3-octanol was obtained. A 3,400-ml charge was redistilled in column 18 in order to obtain a sample for physical properties.

2,3-Dimethyloctenes. The 2,3-dimethyl-3-octanol was dehydrated over alumina at $300^{\circ} \mathrm{C}$. A total of $5.85 \mathrm{~kg}$ (37 moles) of 2,3-dimethyl-3-octanol was passed through the reactor to yield $555 \mathrm{ml}$ of water (30.8 moles, $83.5 \%$ ) and $5.38 \mathrm{~kg}$ of organic material. A charge of this material was fractionated in column 20 in order to obtain pure olefin samples. Of the three most probable olefins, only one was obtained pure enough for physical constants. The properties of this olefin agreed with those previously reported [13] for 2,3dimethyl-3-octene.

2,3-Dimethyloctane. The 2,3-dimethyloctenes (4 kg, 28.6 moles) was hydrogenated using nickelon-kieselguhr catalyst at $140^{\circ} \mathrm{C}$. The initial hydrogen pressure was $1,300 \mathrm{lb} . /$ in. $^{2}$ Fractionation of the crude 2,3-dimethyloctane in two charges in column 20 gave $2.26 \mathrm{~kg}$ of 2,3-dimethyloctene bp $163.3^{\circ}$ to $164.8^{\circ} \mathrm{C}$ (uncorrected), $n_{D}^{20}$ 1.4146-47, as well as a sample for the determination of physical properties. The purest material for shipment was selected by means of interferometer examination, and amounted to $1.55 \mathrm{~kg}$ of purified 2,3-dimethyloctane, bp $163.95^{\circ} \mathrm{C}$, boiling range (20 to 80 percent) $0.015^{\circ} \mathrm{C}, n_{D}^{20} 1.41493$.

\section{1-Hexene}

This hydrocarbon was prepared by the dehydration of 1-hexanol.

Commercial 1-hexanol (32 liters) was distilled in columns 25 to 27 in eight runs. The composite data of these runs were as follows: bp less than $146^{\circ} \mathrm{C}, 52 \mathrm{ml} ; \mathrm{bp} 146^{\circ}$ to $153^{\circ} \mathrm{C}, 2,525 \mathrm{ml}$; bp $153^{\circ}$ to $155^{\circ} \mathrm{C}, 1,066 \mathrm{ml}$; bp $155^{\circ}$ to $158^{\circ} \mathrm{C}$, $26,900 \mathrm{ml}$; and residue $180 \mathrm{ml}$. The purpose of this distillation was to remove the 2-ethylbutanol (bp $146^{\circ}$ to $153^{\circ} \mathrm{C}$ ) from the 1-hexanol (bp $155^{\circ}$ to $158^{\circ} \mathrm{C}$ ). This carbinol would dehydrate to give hexenes boiling close to 1-hexene and therefore difficult to separate.

The distilled 1-hexanol (11.5 kg, 114 moles) was dehydrated over alumina at $400^{\circ} \mathrm{C}$. From this dehydration there were obtained $1,985 \mathrm{ml}$ (110 moles) of water and 13 liters of crude hexenes. This represented 98 percent dehydration on the basis of water recovered. The crude olefin was dried and distilled in column 21 to yield the following fractions: bp less than $60^{\circ} \mathrm{C}, 50 \mathrm{ml}$; bp $60^{\circ}$ to $64^{\circ} \mathrm{C}, 3,970 \mathrm{ml}$ (1-hexene); bp $64^{\circ}$ to $65^{\circ} \mathrm{C}$, $3,820 \mathrm{ml}$; bp $65^{\circ}$ to $67^{\circ} \mathrm{C}, 3,200 \mathrm{ml}$ (2-hexenes); bp $67^{\circ}$ to $88^{\circ} \mathrm{C}, 950 \mathrm{ml}$; and residue $1,400 \mathrm{ml}$. This distillation was very rough and no attempt was made to obtain pure samples.

The stripped hexenes were redistilled in two runs of approximately 4 liters each in columns 19 and 20. From this distillation there was obtained $3.2 \mathrm{~kg}$ (4.2 liters) of purified 1-hexene, bp $63.47^{\circ} \mathrm{C}$, boiling range $(20$ to $80 \%) 0.006^{\circ} \mathrm{C}, n_{D}^{20} 1.38777$, in addition to a sample for physical properties.

In order to determine the ratio of 1 -hexene to the 2-hexenes a small charge $(1,500 \mathrm{ml})$ of crude dehydrated 1-hexanol was distilled in column 18 . This distillation gave the following fractions: Fraction 1 , bp $37^{\circ}$ to $60^{\circ} \mathrm{C}, n_{D}^{20} 1.386,15 \mathrm{~g}$; fractions 2 to 9 , bp $60^{\circ}$ to $65.7^{\circ} \mathrm{C}, n_{D}^{20} 1.3880-86$, $455 \mathrm{~g}$; fractions 10 to $11 \mathrm{bp} 65.7^{\circ}$ to $68.0^{\circ} \mathrm{C}$, $n_{D}^{20} 1.3899$ to $1.3934,120 \mathrm{~g}$; fractions 12 to $14 \mathrm{bp}$ $68.0^{\circ}$ to $69.0^{\circ} \mathrm{C}, n_{D}^{20} 1.3955-71,148 \mathrm{~g}$; Fraction 15 , bp $69^{\circ}$ to $107^{\circ} \mathrm{C}, n_{D}^{20} 1.4026,37 \mathrm{~g}$; and residue $120 \mathrm{~g}$. This distillation indicated the ratio of 1-hexene to the 2 -hexenes to be 2 to 1 .

\section{4-Methyl-1-pentene}

This hydrocarbon was prepared from the condensation of isopropylmagnesium chloride and allyl chloride.

Isopropylmagnesium chloride was prepared from $3.15 \mathrm{~kg}$ (131 g atom) of magnesium and 11 $\mathrm{kg}$ (140 moles) of isopropyl chloride in the same manner as described for $n$-butylmagnesium chloride in the preparation of 5-nonanol.

Allyl chloride, $10 \mathrm{~kg}$ (131 moles) was mixed with 10 liters of ether and the solution was added to the Grignard reagent over a period of 3 days. During this time the temperature of the reaction mixture was held at $5^{\circ} \mathrm{C}$. The reaction mixture was worked up in the usual manner and the ether solution of 4-methyl-l-pentene was dried over potassium carbonate. The ether was stripped off in column 21 in several charges and all the residues from the stripping runs were combined and redis- 
tilled in column 21. From this distillation there was obtained $6.3 \mathrm{~kg}$ (75 moles, 57 percent) of 4-methyl-1-pentene, bp $50^{\circ}$ to $56^{\circ} \mathrm{C}$. About 1 liter of diallyl remained as residue.
A charge of 4 liters of crude 4-methyl-1-pentene was distilled in column 19 to yield 2.5 liters (1.5 $\mathrm{kg}$ ) of purified 4-methyl-1-pentene, fp $-153.95^{\circ}$ $\mathrm{C}$, and a sample for physical properties.

\section{Appendix}

\section{Determination of Physical Constants}

Samples of $n$-heptane and 2,2,4-trimethylpentane are submitted to this Bureau, through the American Society for Testing Materials, for certification as standard reference fuels for knock rating work. Certification of these samples, representative of lots of material of over 100,000 gal, is based, in part, on the determination of selected physical constants and the comparison of these physical constants with those measured on high-purity material. These constants are: boiling point, boiling range (20 to $80 \%$ distilled), freezing point, density, and refractive index. All other hydrocarbons and intermediates synthesized in the Hydrocarbons Research Laboratory of the Engine Fuels Section are characterized by measurement of these properties, supplemented by measurement of: change in boiling point with pressure near $760 \mathrm{~mm} \mathrm{Hg}$, change in density with temperature, and change in refractive index with temperature.

Descriptions of the methods used have been published from time to time $[6,16,18]$, but it is considered advisable to present the latest improvements used as part of a complete description. This appendix is such a description.

\section{Freezing Point in Air}

(a) Apparatus

The apparatus used for the determination of freezing points in these laboratories contains features adopted from the apparatus of Mair [14], Roper [15], Brooks, Howard, and Crafton [16], and Glasgow, Streiff, and Rossini [5]. This apparatus is shown in figure 5.

The sample is placed in tube $C$, which is $26 \mathrm{~mm}$ outside diameter and $273 \mathrm{~mm}$ in length. It is rounded at the bottom, and the throat is reinforced with heavy glass so that the tube may be gripped tightly with a clamp in order to hold it in place when the freezing substance becomes viscous.

The electrically heated tube is shown in detail in figure 6 . It is constructed from a pair of glass tubes ( $K$ and $L$ ), 41 and $36 \mathrm{~mm}$ in outside diameter and $240 \mathrm{~mm}$ in length. These tubes are closed at the base and fit within each other. About the inner tube, $L$, is wound 49 turns of No. 32 Calido wire. This possesses a resistance of $185 \mathrm{ohms}$ at room temperature. The resistance wire is secured in place with scotch tape and the annular space filled with paraffin wax. This wax was found necessary in order to protect the wire from corrosion from atmospheric condensation. At the top of the tube the resistance wire is silver soldered to copper leads $M$. The rates of cooling and warming are controlled with high sensitivity by means of a 1-amp variable transformer. Within the inner heating element tube is placed a brass tube $D$ closed

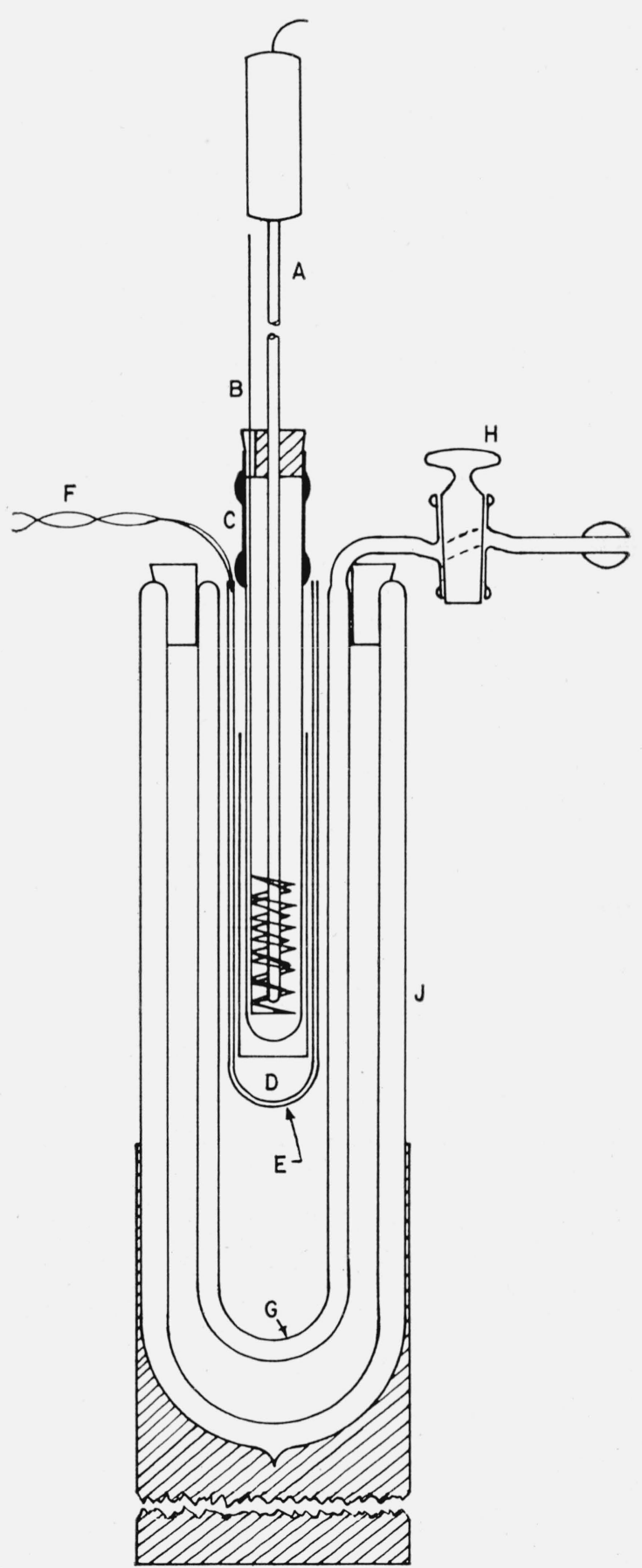

Figure 5. Freezing-point apparatus. 
at the base and having a diameter of $30 \mathrm{~mm}$ and a length of $150 \mathrm{~mm}$. This tube is covered with smooth aluminum foil. The purpose of this tube is to equalize the heat transfer over the entire sample and to shield the thermometer from outside radiations.

The cooling rate is roughly controlled by means of an unsilvered Dewar $(G)$ (fig. 5) in which the degree of

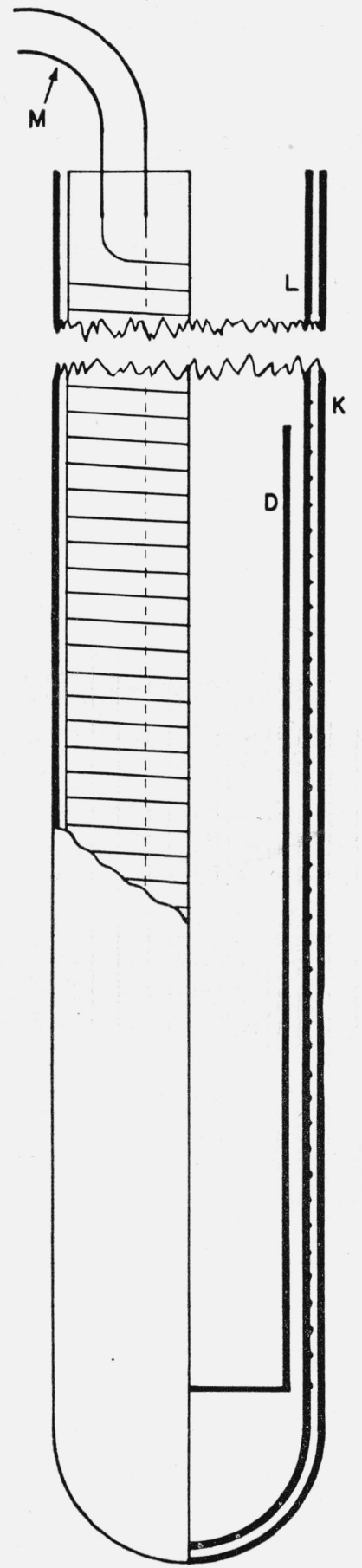

Figure 6. Heating tube of the freezing-point apparatus. evacuation may be varied. This Dewar is $50 \mathrm{~mm}$ inside diameter, $69 \mathrm{~mm}$ outside diameter, and $38 \mathrm{~cm}$ in length, and is evacuated through a high vacuum stopcock $(H)$. For this purpose a mechanical oil pump has proved adequate. A number 18 spherical joint connects the Dewar to the pump line. Glass wool is placed in the bottom of this tube to help support the heating tube.

The coolant reservoir is a silvered Dewar $95 \mathrm{~mm}$ inside diameter and deep enough to carry the rest of the ensemble. Liquid nitrogen is used as the coolant for materials freezing below $-50^{\circ} \mathrm{C}$, and dry ice in carbon tetrachloride and chlorofrom for higher-freezing materials.

The sample is stirred by stirrer $B$ (fig. 5). Two types of this double helical stirrer are shown in figure 7 . The first (A) is made to fit the tube snugly and the edges are machined flat in order to scrape the walls of the tube. The second $(B)$ is a loose-fitting double helical stirrer in which the turns, except the bottom one, are held rigid by the vertical rod. This second stirrer was found to be the more satisfactory and has since been used for all determinations. It is made of 0.078-in. nichrome wire. The outer helix is $19 \mathrm{~mm}$ in diameter, the inner $14 \mathrm{~mm}$, and the helical length is about $6 \mathrm{~cm}$. The stirrer is driven by means of a crank operated by a direct current motor, the speed of which may be varied with a rheostat. The length of the stroke is $4.5 \mathrm{~cm}$. With this stirrer, no difficulty has been encountered in obtaining equilibrium freezing point curves, even for very high purity $n$-heptane and 2,2,4-trimethylpentane.

The temperature is measured by means of a platinum resistance-thermometer held in place by a cork which is

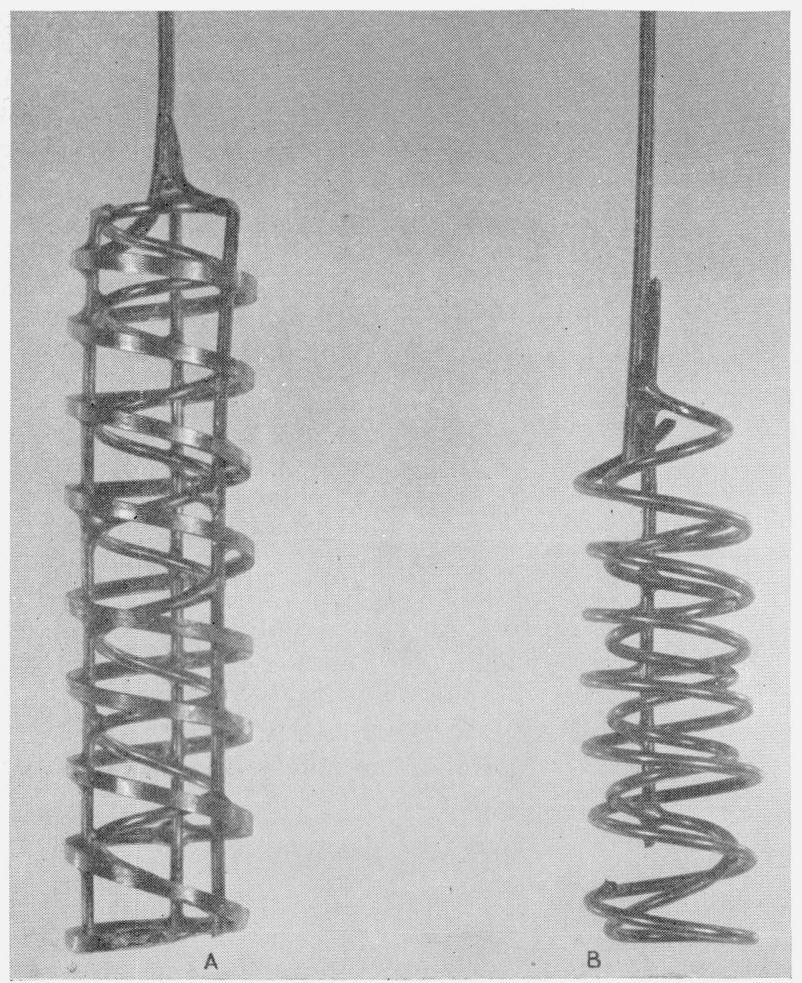

FiguRE 7. Freezing-point stirrer. 


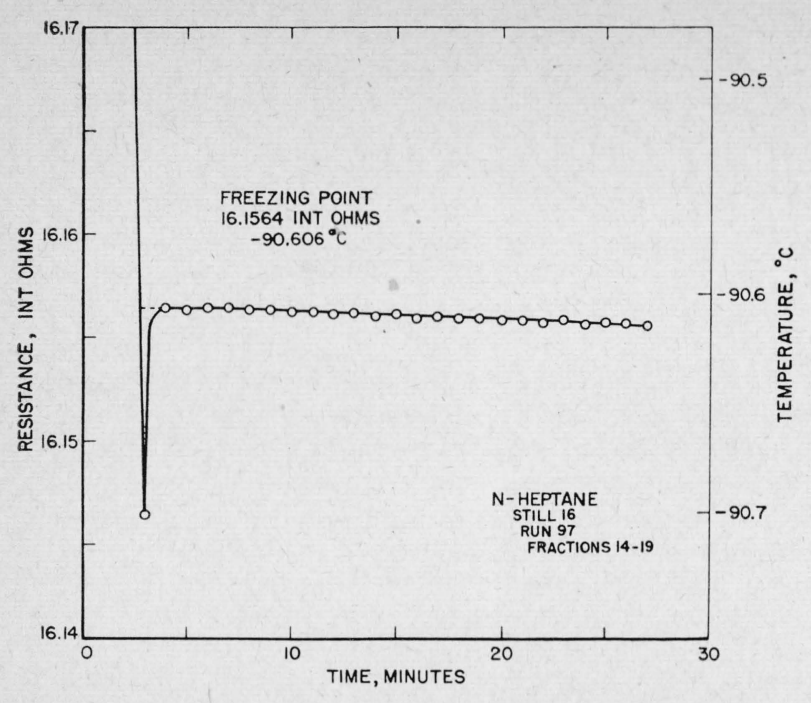

Figure 8. Freezing curve of n-heptane.

notched to provide room for the stirrer. The resistance is measured by means of a G-2 Mueller bridge with the usual accessories.

\section{(b) Determination of the Freezing Point}

The apparatus is assembled as shown in figure 5 with sufficient sample in the freezing tube to cover the stirrer at the top of the stroke. The outer Dewar is filled with liquid nitrogen to within about $1 / 2 \mathrm{in}$. of the top and kept at this level. The stirrer is run at a rate of about 60 strokes per minute.

When the temperature reaches 20 to 30 degrees above the expected freezing point, the vacuum pump is started and the pumping continued until the temperature has fallen to 3 to 5 degrees above the expected freezing point, at which time the stopcock is closed and the pump stopped. The electric heater is started 10 to 15 degrees above the freezing point and set to control the cooling at the desired rate. Near the expected freezing point this rate is 0.25 to 0.40 degree per minute. The voltage setting on the variable transformer is based on previous determinations of cooling rates at various voltages and temperatures.

Readings are begun at 1.0 to 1.5 degrees above the expected freezing point. At this time the cooling rate should be 0.25 to 0.40 degree per minute. Readings are taken each minute and when the material supercools more than 0.2 degree below the expected freezing point it is seeded with a cold rod. At least 30 readings should be taken at 1-minute intervals after the curve reaches a peak following supercooling. The curve is plotted and interpreted according to the method of Taylor and Rossini [17]. A typical freezing curve is shown in figure 8 .

If a melting curve is desired the heater is set at a predetermined voltage to give a warming rate of $0.4 \mathrm{deg} C$ in the liquid phase. The other experimental and calculative details are the same as with a freezing point.

This freezing point apparatus has been found to give: 1. Rapid cooling with substances that freeze at low femperature. By maintaining the air at atmospheric pressure within the unsilvered Dewar, it is possible to reach the neighborhood of the freezing point much more quickly than can be done with a fixed vacuum Dewar. It is not necessary to start evacuating the Dewar until 20 to 30 degrees above the expected freezing point.

2. Accurate control of the cooling and warming rates. With the electric heater it is possible to control the cooling or warming rate quite accurately from 0.5 degree per minute cooling to 0.5 degree per minute warming.

3. Efficient stirring, which prevents excessive supercooling and aids quick recovery to the equilibrium state, only 3 to 5 minutes being necessary for recovery.

4. Equilibrium freezing curves, presumably obtained because packing of frozen material in the bottom of the tube is retarded by the new stirrer.

5. A precision of measurement of freezing points of about $0.003 \operatorname{deg} \mathrm{C}$.

\section{Boiling Point}

The equipment for determining the distillation curves on $n$-heptane, 2,2,4-trimethylpentane, and other compounds as used now has been modified from the apparatus described in reference [19] and is similar to the apparatus designed by Mair [14].

\section{(a) Apparatus}

The apparatus used in the determination of boiling points is shown in figure 9.-The pot and column assembly is made by sealing a length of $25-\mathrm{mm}$ tubing to a $125-\mathrm{ml}$ round bottom flask taken from an ordinary distilling flask so that the over-all length is $52 \mathrm{~cm}$. A side arm of

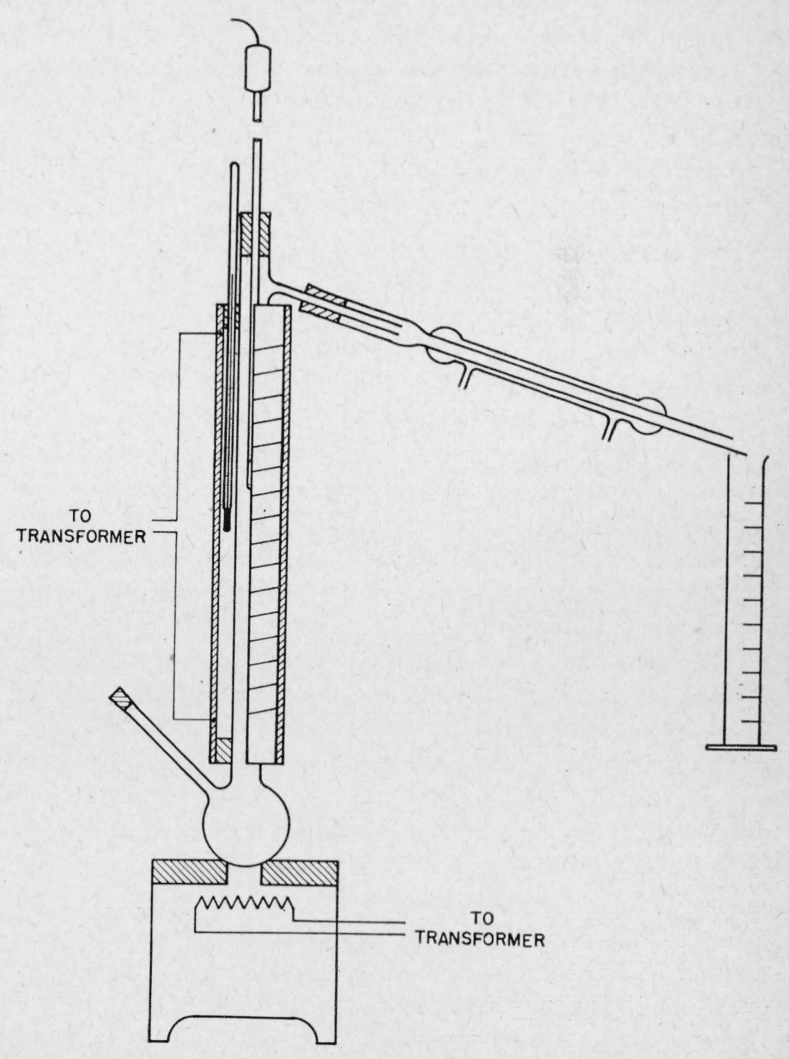

Figure 9. Boiling-point apparatus. 
$10-\mathrm{mm}$ tubing is sealed onto the flask at a 45 -degree angle to the column. A length of 56- $\mathrm{mm}$ tubing $37 \mathrm{~cm}$ long, which has two glass knobs sealed $1 \mathrm{~cm}$ from the top and bottom, is slipped over the column and an upper side arm is sealed into place. The latter is made of $8-\mathrm{mm}$ tubing sealed to the column $5.5 \mathrm{~cm}$ below the top at an angle of about $18 \mathrm{deg}$ below the horizontal. The jacket is separated from the column by two No. 30 corks, which are first bored and then split across the middle to facilitate placing. In one of the top halves is bored a small hole to carry the thermometer $\left(0^{\circ}\right.$ to $\left.360^{\circ} \mathrm{C}\right)$ for determining the temperature of the jacket. These corks are put in place so that they fit tightly. The jacket is wound with No. 22 (B \& S) chromel wire spaced $2 \mathrm{~cm}$ apart, and anchored to the glass knobs at the end of the jacket. The jacket and wire are wrapped with one layer of $1 / 8$-in. asbestos and finally covered with smooth tin foil. Corks are used for closing the charging tube and for carrying the resistance thermometer and for connecting the side arm into the condenser. The current input into the jacket heating wire is regulated by a variable transformer.

The pot is heated by a 660-watt laboratory heater, controlled by a 6-ampere variable transformer. The material distilled through the apparatus is condensed in a $300-\mathrm{mm}$ West type condenser and caught in a $100-\mathrm{ml}$ graduate.

The thermometric system used in the determinations consists of a Mueller resistance bridge, a platinum resistance thermometer, and a precision galvanometer. The galvanometer is adjusted so that a change of $0.0001 \mathrm{ohm}$ on the bridge causes a deflection of about $4 \mathrm{~mm}$ on the galvanometer scale. The resistance thermometer is the standard four-lead type having a resistance of about 25.5 ohms at the ice point. This thermometer is calibrated every two years by measuring the resistance at the melting point of ice and the boiling points of oxygen, water, and sulfur.

\section{(b) Method}

The apparatus is assembled so that the end of the resistance thermometer extends about 6 in. below the side arm. Care must be taken that the bulb of the thermometer does not touch the walls of the column as this makes for erratic readings. The jacket thermometer is adjusted so that the scale readings are visible above the jacket beginning at about $25 \mathrm{deg} \mathrm{C}$ below the boiling point of the liquid. The receiver, a, $100-\mathrm{ml}$, graduate is adjusted so that the distillate from the condenser runs down the inner side of it.

While the sample is being heated in the pot, the jacket temperature is adjusted to 2 to $5 \mathrm{deg} \mathrm{C}$ below the boiling point of the material being distilled. When the liquid begins to simmer, the barometer reading, barometer temperature, and the time are taken. This procedure is repeated after $10,25,40,55,70,80$, and $90 \mathrm{ml}$ have been distilled. The first drop to leave the sidearm after the vapor ring comes up is taken as the zero reading. At this point the resistance of the thermometer and the time are recorded. This is repeated at 2, 4, 6, 8, and $10 \mathrm{ml}$ and every $5 \mathrm{ml}$ thereafter until $90 \mathrm{ml}$. The rate of distillation is maintained at $5 \mathrm{ml}$ per 1.0 to $1.25 \mathrm{~min}$.

It has been advisable to take all readings with the commutator of the bridge in the normal position. The correction for the reverse reading is made by determining the resistance of the thermometer with the commutator in the reverse position after the $30,35,45$, and $50 \mathrm{ml}$ readings.

Immediately after the distillation is completed, the barometer should be calibrated by boiling distilled water in the apparatus. This corrects not only for the errors in the instrument but also the personal error of the operator, and, for compounds boiling near $100^{\circ} \mathrm{C}$, for thermometer error also.

The temperatures are calculated from the resistances in the usual manner. The barometer is corrected for temperature and for the difference between the observed barometric pressure and the true pressure as determined by the water. The time furnishes the common ground of comparison between temperature and pressure.

\section{Refractive Index}

Refractive indices are measured on a precision oil refractometer. This instrument is an Abbe-type refractometer with the prisms movable in a near-horizontal plane, rather than in a vertical plane. The scale is calibrated linearly in arbitrary units, and readings are converted to refractive index by use of a set of conversion tables furnished with the instrument. The instrument is readable to about 0.002 unit in the arbitrary scale, which, in the neighborhood of $n_{D}{ }^{20} 1.39$, is equivalent to about 0.000012 unit of refractive index. The reproducibility of readings by a skilled operator is about 0.00002 unit of refractive index. Temperature is controlled by circulation of water from a constant-temperature bath through a chamber around the prisms. The constant-temperature bath is of standard design, equipped with two mercury thermostats, one set at near $20^{\circ} \mathrm{C}$ and the other near $25^{\circ} \mathrm{C}$. The light source is a sodium vapor lamp.

The technique used in measuring the refractive index is: Ten readings are taken on a sample of 2,2,4-trimethylpentane (a working standard), five while approaching the demarcation line from one direction, and five from the opposite direction. The temperature (at the prism) is measured to $0.01^{\circ} \mathrm{C}$ by a mercury thermometer for each reading. These values are averaged. Immediately thereafter a sample of the material to be tested is put into the instrument and ten readings are taken in the same manner. A comparison of the average of these rcadings with that obtained on the working standard gives the difference in refractive index between the working standard and the compound under test. In this way, instrumental errors are practically eliminated. The refractive index of the working standard is measured periodically by comparison with the standard sample of 2,2,4-trimethylpentane (NBS Standard Sample 217), the refractive index of which has been accurately measured (to \pm 0.00002 ) by the Optical Instruments Section.

Recently, refractive indices of certain compounds have been measured by comparison with a standard in a Rayleigh interferometer. This instrument measures the difference in refractive index between two samples with a greater precision (about \pm 0.000004 with a 1 -cm cell in the neighborhood of $n_{D} 1.39$ to 1.40) than the refractometer does. 


\section{Density}

A thin-walled, glass-stoppered picnometer of about 50-ml capacity is used in the determination of density (see fig. 10). Measurements are generally made at temperatures near $20^{\circ}$ and $25^{\circ} \mathrm{C}$.

The sample is placed in the picnometer, filling it nearly to the cap. The picnometer and sample are immersed in a constant-temperature bath and allowed to remain for 1 hr. At the end of this time the sample is drawn from the neck of the picnometer with a capillary tube connected to a vacuum line. The liquid is first drawn out until the level is just above the mark, the end of the capillary run around the walls to dry them, and finally the liquid level is adjusted so that the bottom of the meniscus is level with the line. The picnometer is then stoppered and the bath temperature observed.

The picnometer is dried, immersed in acetone, dried again, and weighed. After weighing, the picnometer is emptied, washed with acetone, and dried. The empty

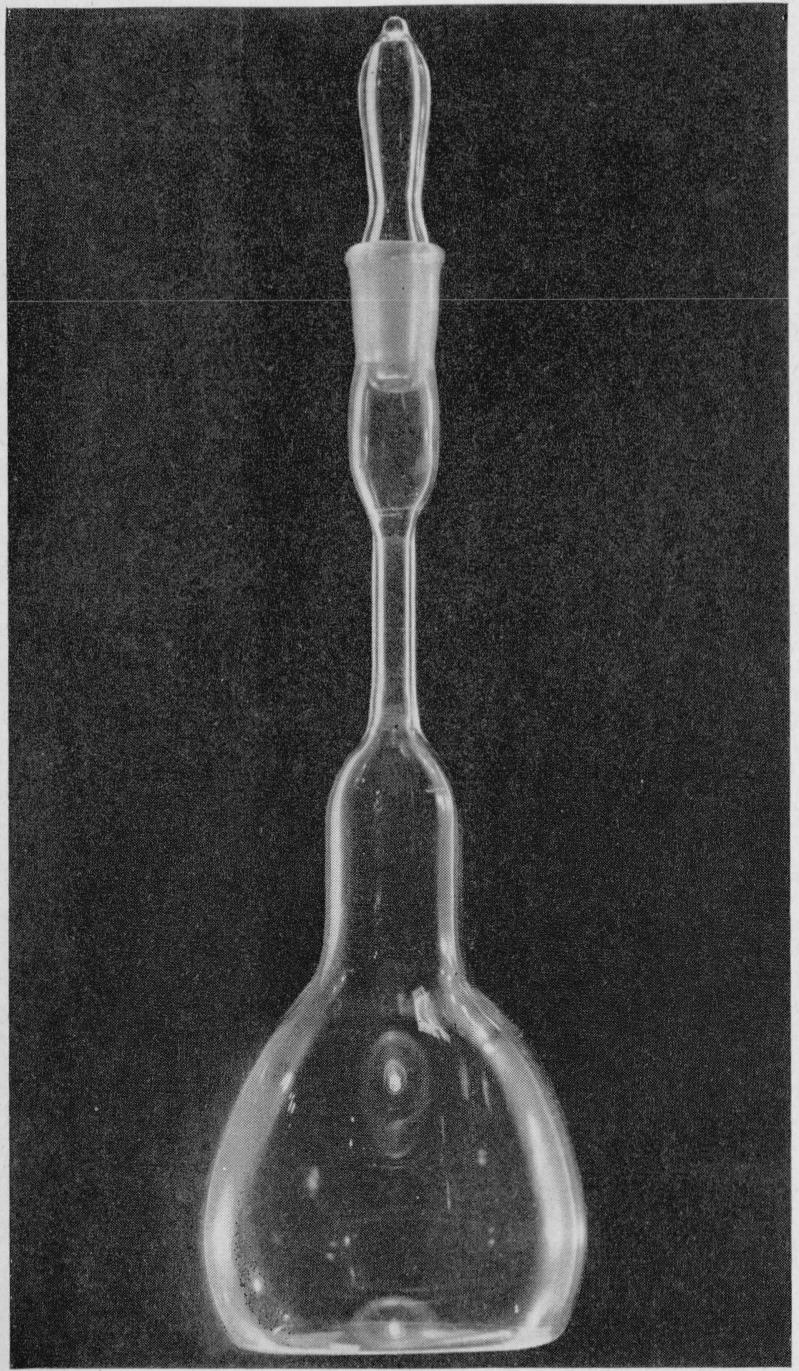

Figure 10. Picnometer used for measuring density. flask is then dipped in acetone, dried, and weighed. Finally, the barometer and barometer temperature are read and the psychrometer reading taken. By suitable calculations, the mass in vacuo is obtained.

The volume of the flask is determined by distilling water into the picnometer and then proceeding as outlined above to obtain the mass of water in vacuo. The density of water at that temperature is taken from tables and the volume of the flask calculated. The flask is calibrated at both temperatures.

From these data, the density of the sample at temperatures near $20^{\circ}$ and $25^{\circ} \mathrm{C}$ is calculated and corrected to $20^{\circ}$ and $25^{\circ} \mathrm{C}$.

\section{References}

[1] H. Adkins, Reactions of hydrogen, chapter III (Univ. Wisconsin Press, 1937).

[2] A. W. Francis, Ind. Eng. Chem. 35, 442 (1943).

[3] L. Gatterman and H. Wieland, Laboratory methods of organic chemistry, p. 45 (MacMillan \& Co., Ltd., London, 1941).

[4] H. Gilman and F. Schulze, J. Am. Chem. Soc. 47, 2002 (1925).

[5] A. R. Glasgow, Jr., A. J. Streiff, and F. D. Rossini, J. Research NBS 35, 355 (1945) RP1676.

[6] F. L. Howard, T. W. Mears, A. Fookson, P. Pomerantz, and D. B. Brooks, J. Research NBS 38, 365 (1947) RP1779.

[7] S. P. Mullekin, R. L. Wakeman, and H. T. Gerry, J. Am. Chem. Soc. 5\%, 1605 (1935).

[8] Organic syntheses, second collective volume, p. 179 (John Wiley \& Sons, Inc., New York, N. Y., 1943).

[9] Organic syntheses, second collective volume, p. 408 (John Wiley \& Sons, Inc., New York, N. Y., 1943).

[10] G. S. Parks, T. J. West, and G. R. Moore, J. Am. Chem. Soc. 63, 1133 (1941).

[11] A. J. Streiff, E. T. Murphy, J. C. Cahill, H. F. Flanagan, V. A. Sedlak, C. B. Willingham, and F. D. Rossini, J. Research NBS 38, 53 (1947) RP1760.

[12] A. J. Streiff, E. T. Murphy, J. C. Zimmerman, L. F. Soule, V. A. Sedlak, C. B. Willingham, and F. D. Rossini, J. Research NBS 39, 321 (1947) RP1833.

[13] F. C. Whitmore and W. L. Evers, J. Am. Chem. Soc. 55, 812 (1933).

[14] B. J. Mair, J. Research NBS 9, 457 (1932) RP482.

[15] E. E. Roper, J. Am. Chem. Soc. 60, 1693 (1938).

[16] D. B. Brooks, F. L. Howard, and H. C. Crafton, Jr., J. Research NBS 23, 637 (1939) RP1259.

[17] W. J. Taylor and F. D. Rossini, J. Research NBS 32, 197 (1944) RP1585.

[18] D. B. Brooks, R. B. Cleaton, and F. R. Carter, J. Research NBS 19, 319 (1937) RP1027.

[19] C. W. Kanolt, BS Sci. Pap. 20, 619 (1925) S520.

Washington, July 27, 1949. 